\title{
INFLUENCE OF THE MAGNETIC FIELD ON THE LIVING ORGANISMS AND HUMANS
}

\author{
Stefan Naydenov, Sonia Petkova, Petar Getsov, Garo Mardirossian
}

\begin{abstract}
Summary: The question of the influence of magnetism on biological objects for years has been a debate with many contradictory opinions. The article provides a brief overview of publications and various and contradictory views on the influence of magnetic fields on living organisms and humans. An explanation is sought for findings made in various scientific studies, as well as an answer to the question: Can a permanent magnetic field be useful for our health and under what conditions?
\end{abstract}

Key words: magnetic field, health, diagnostic, physiotherapy, physiological response

One of the areas of application of the permanent magnetic field, which is no longer contested, is diagnostic and diagnostic equipment.

In a report to the World Health Organization [1], an international panel of experts reported: "The modern generation of magnetic resonance imaging devices used in clinical practice is working with permanent magnetic fields with an intensity of 0.3 to $2 \mathrm{~T}$ (3000 to $20,000 \mathrm{G})$ and RF fields with frequencies up to $100 \mathrm{MHz}$. Weak spatial gradients around $0.001 \mathrm{~T}(10 \mathrm{G})$ are used to determine the tissue location of the MR signal."

In our opinion, a crucial point in this report is the finding that even the weak magnetic gradient $10 \mathrm{G}-$ acts on the tissues and this influence is used in modern medical diagnostic apparatuses. A fact that refutes all "scientific" doubts about the ability of a permanent magnetic field, including weak and medium fields, to affect the human body.

T. Truong (T. Truong), B.D. Glumer (B. D. Clymer), and others [2] examined the different tissue response in the human head of a mega static magnetic field $(8 \mathrm{~T}=80,000 \mathrm{G})$ by three-dimensional digital simulations. The difference in the magnetic sensitivity of cells and tissues, especially when exposed to mega magnetic fields (over $0.5 \mathrm{~T}$ ), is a valuable mechanism used in magnetic resonance imaging.

Brittenham, Farrell, and others [3] make direct non-invasive magnetic measurements of liver iron deposits with a specially designed superconducting quantum device (SQUID) of 20 healthy volunteers and 110 patients with liver disease, iron deficiency, hereditary haemochromatosis or iron overload due to blood transfusion. They combine magnetic in vivo liver iron overload measurements with chemical in vitro measurements in liver biopsy. Through their research, Britton, Farrell and others demonstrate that magnetic measurements of iron depots provide a new quantitative method for early detection of hereditary hemochromatosis and for rapid assessment of liver transfusion treatment regimens due to blood transfusion.
And while there is a hopeless consensus that in modern medicine the permanent magnetic field is an inevitable tool and a factor in diagnostics, there is still controversy, often and with no scientific arguments, to what extent the magnetic field is useful for the treatment of various diseases. There are theories that are still trying to question the biological effects of a static magnetic field or its effect on particular subjective symptoms.

In the formation of biological effects in magnetic fields, processes from different levels of organization of living organisms are essential, starting with physical processes and ending with complex adaptation biological processes [4].

Experts from different fields analyze the question of the influence of the magnetic field on living organisms from its expert point of view. The medics are exploring organ sensitivity and general physiological processes to the magnetic field. Biologists are looking for cellular and subcellular structures to form biological signals in response to the influence of the magnetic field. Biochemists analyze units of biochemical reactions, the speed of which may depend on the magnetic field parameters. Biophysicists are attempting to emit magneto-sensitive magnetic field interactions with relatively simple molecular structures. It is at this level that complex spectral connections of biochemical processes arise with the biotropic parameters of the magnetic field.

Studies on the influence of strong magnetic fields on the human body show significant growth with the development of diagnostic and physiotherapy equipment in medicine and mass influx of mobile phones in everyday life.

Over the past 3-4 decades various studies have been conducted to influence strong permanent magnetic fields on laboratory animals. Many of the findings made on this subject have been analyzed in a review by R. Sanders (Saunders) on studies conducted mostly on mammals [5]. Four main areas have been studied: the nervous system, the cardiovascular response, reproduction and development, and 
genotoxicity and cancer. Reactions found during exposure to permanent fields above $4 \mathrm{~T}$ are consistent with those observed in volunteer studies. Increased blood flow around the heart has been established. There were no clinically significant changes in $1 \mathrm{~T}$ field effects. There were no side effects on reproduction and on the development and growth of tumors. Overall, however, Sanders emphasizes that research is insufficient to draw firm conclusions.

Various results on the impact of a $3000 \mathrm{G}$ force field on cancer cells are received by Dr. Albert Roy Davis and Walter Rowles [6] as well as the American scientist Cathy Solis [7]. Their studies contradict Sanders' analysis of the influence of the magnetic field on tumor cells.

In studies on the development of cancer cells in rats and mice subjected to the impact of a north pole on a $3000 \mathrm{G}$ magnet, from 45 to 60 minutes, $2-3$ times a day, Dr. Davis has found a reduction in cancer division cells and analgesia. In animals under the influence of the southern magnetic pole, the cancer cells develop more rapidly [6].

Ganshiam Singer Birla and Colelet Hemlin describe in their book Magnetotherapy the results of a study by Kathy Solis, who has been investigating for 4 years the influence of $3000 \mathrm{G}$ bipolar magnetic field on cancer-bearing animals and found that the number of cancer cells decrease, but after the magnetic field has ceased, their number is recovering.

In his study, LY Pyrusian and A. Kuznetsov also reviewed the possible mechanisms of reaction of living organisms to strong magnetic fields above $1 \mathrm{~T}(1 \mathrm{~T}=10000 \mathrm{G})$ [8].

The influence on the heart rhythm of a highly constant magnetic field is described by P. Jehenson and D. Duboc and [9]. The action of $2 \mathrm{~T}(20,000 \mathrm{G})$ magnetic field was studied by 24 hour electrocardiographic observation in 12 healthy volunteers for 1 hour before exposure, one hour during exposure, and 22 hours after exposure to the magnetic field. Another group of 4 volunteers were exposed to a magnetic field with a force of $1 \mathrm{~T}$ and a control group of nine humans was exposed to a field of $0 \mathrm{~T}$ intensity.

In the $2 \mathrm{~T}$ magnetic field group, the average heartbeat length was measured $912 \mathrm{~ms} \pm 83$ before exposure to the magnetic field. A significant increase in heart rate of $17 \%$ was observed after 10 minutes of magnetic impact. No significant deviations were recorded during the test. Heart rhythm restores its normal values 10 minutes after cessation of the magnetic field. No cardiac disturbance and arrhythmia was detected during magnetic radiation and 22 hours afterwards (during 24-hour monitoring). No statistically significant changes in cardiac activity were observed in the other two magnetic field strengths $1 \mathrm{~T}$ and $0 \mathrm{~T}$.

Yousef Haik, Vinay Pai and Ching Chen reported experimental results showing that the rate of blood flow in gravity decreased by $30 \%$ when it was under the action of a mega-magnetic field of intensity $10 \mathrm{~T}$ $(100000 \mathrm{G})$ [10]. The reduction in blood flow rate is due to an increase in blood viscosity under the influence of the mega magnetic field.

There are a number of mathematical models for the influence of mega magnetic fields on the blood $[11,12]$ and others. Since the influence of mega magnetic fields is not the subject of our research, we will not analyze these studies in detail.

Strong magnetic fields with an intensity of more than 2000-3000 $\mathrm{G}$ and mega-magnetic fields with an intensity of several tens of thousands of $G$ can be used for short-term therapy or instant diagnostics but are not suitable for long-term effects because they hinder vital processes.

Grace (Grisset, J. D.) found in a study [13] that the influence of the magnetic field on the human body depends on its strength and the duration of its impact. Excessive doses of the magnetic field can cause a negative reaction to organs and systems in the body. Gray's statement confirms the basic pharmacology law of Arnd Schultz.

Stratznigg A. [14] reported: "The results of experimental studies have shown that strong magnetic fields in long-term effects cause persistent degenerative dystrophic changes in cells and tissues."

Mega magnetic fields in the diagnostic apparatus have no alternative, but the time of magnetic field impact on diagnostics is low. In therapy, however, especially if the procedures are for a longer period of time, it is best to choose variants using a magnetic field below $3000 \mathrm{G}$.

Significantly less are studies of the magnetic response of magnetic fields below $3000 \mathrm{G}$ compared to mega magnetic fields, although they are more suitable for therapy and are the only possible option for magnetic prophylaxis.

There are theories that deny in whole or in part the possibility of a biological response when exposed to a low or medium magnetic field. According to Binggi, the existence of a biological effect due to the influence of a weak and medium static magnetic field is impossible, either by theoretical models or by experimental [15]. However, such experiments are made in the scientific literature. For example, Aider R. K. [16] as 
well as Picard V. F. and Moros FG [17] analyze physical models of hypothetical processes offered by literature from the fundamental basis of magnetism by refuting them. As Bingley notes, the rebuttalations made by them do not contain constructive elements and their findings have not been scientifically proven [15].

Fundamental significance for demonstrating the beneficial effect and therapeutic effect of static magnetic fields with a force below $3000 \mathrm{G}$ are the studies of Dr. Kioki Nakagawa, chief physician at the Tokyo Hospital. Twenty years (1953-1976) he studied the therapeutic effect of static magnetic fields with an intensity of $400 \mathrm{G}$ to $3000 \mathrm{G}$.

The Japanese scientist proves the link between the existing magnetic deficit in the body and the symptoms of ailments he calls the Magnetic Deficiency Syndrome (MDS) [18]. Symptoms of the syndrome observed by him and his team are: "stiffness" of the shoulders, back and neck, unstable lumbago, chest pain without a specific cause, common headache and weight in the head, vertigo and insomnia without clear reasons, chronic constipation, general fatigue, an imbalance of the central nervous system or the time of it, etc. In other words, this is a syndrome in which the objective pathological condition (the cause of the symptoms) can not be established by routine physical and clinical studies. Symptoms of MDS are not improved with different procedures but are affected by magnetic field effects.

In 1958, Dr. Nakagawa and his team, as part of the study of "Magnetism and Living Organisms", found a fairly high percentage of alleviation of shoulder stiffness in patients wearing bracelets with permanent magnetic field radiation. Data from the study are published in the "Japanese Journal of Internal Medicine" [19], "Japan Medical Journal" [20] and "Chugai Medical Publication" [21].

Dr. Fujimoto (Fujimoto) makes an analysis of the successful magnetic field response on the same subjective symptom [22].

Kimura and a team reported a study of two types of magnetic bracelets with a magnetic field strength of $470 \mathrm{G}$. An improvement in subjective symptoms was achieved without altering the composition of blood serum - fat and protein and their fractions [23].

In 1974, Nakagawa's team conducted a study to treat the stiffness and perception of 11,648 patients, divided into four groups, with a static magnetic field patch. The magnetic field has a successful effect on the symptoms of $90 \%$ of the patients involved in the study [24]. Dr. Nakagawa also reported a group of 120 patients using rare Earth Cobalt Magnetic Neutrals with a force of $1300 \mathrm{G}$ for a period of two weeks, again for therapy of stiffness in the shoulders. $96.3 \%$ of the cases were affected, and clinical trials did not detect any harmful effects on the human body [25].

In 1976, Horie [26] reported clinical trials of a magnetic ring. Significant response (to varying degrees) was achieved in $76.3 \%$ to $97.3 \%$ of patients in the treatment of shoulder stiffness. A control group with non-magnetic rings was involved in the study. Dr. Horrie found a significant difference in response in both groups.

Dr. Shimohira and team [27] perform parallel studies of the same magnetic ring to treat the same subjective symptoms. And this research team uses a control group with non-magnetic rings. They found that magnetic rings affect $80.2 \%$ of patients, while non-magnetic rings show $6.3 \%$ efficacy (placebo effect).

Takahashi's research team [28] reported a high rate of effectiveness in treating shoulder stiffness by using a magnetic neck with an intensity of 700-900 G. In clinical trials, there was no adverse effect on patients.

In the period 1974-1975 the teams of Dr. Sugiura [29], Dr. Otta (Ohta) [30] and Baba [31] conducted parallel studies of a magnetic necklace in patients with perceptions and stiffness in the shoulders. All three groups included control groups using non-magnetic necklaces. Dr. Sigurma reported a significant difference in response between the group with magnetic and non-magnetic necklaces, respectively $78 \%$ vs. $17 \%$ [29]. The results for Doctor Ota are $65 \%$ efficiency of magnetic products vs. $20 \%$ for non-magnetic [30]. Dr. Baba reported a 16-patient response from the 20 field studies [31].

Dr. Shimada makes a test of the same necklace in three weeks, alternating magnetically with a nonmagnetic necklace. This magnetic therapy achieves $75 \%$ efficiency [25].

As a result of the research of Dr. Kiocchi Nakagawa and his team, as well as the other Japanese physicians cited above, magnetotherapy is recognized as an official treatment method in Japan. Magnetic devices emitting a permanent magnetic field are included in the official list of medicines of the Japanese Ministry of Health.

Segal, Toda, and others conduct a static magnetic field impact study on pain caused by rheumatoid arthritis [32]. Patients with rheumatoid arthritis randomly selected are divided into two 
groups - primary (38) and control (26). Magnetic devices with bipolar magnetic field were used in the main group at $1900 \mathrm{G}$ and in the $720 \mathrm{G}$ control, which affected patients for 1 week. There was a difference between the pain response in the baseline and the control group at the end of the period $(\mathrm{p}=$ $0.23)$ and in the control $(p<0.01)$. In terms of controlled parameters of inflammatory C-reactive protein and erythrocyte sedimentation rate no difference was found between the two groups. The study concludes that there is no statistically significant difference in pain reduction [32].

From a scientific point of view, the study is not planned correctly. It is not clear why the control group is also exposed to a magnetic field, albeit less. Thus, the true placebo effect can not be recorded. In addition, no criterion for a statistically significant difference in pain reduction was defined. For comparison, in a study by Stewart Richmond, with a similar target of a statistically significant difference in the pain response measured by VAS, $\mathrm{p}<0.05$ was taken.

Stuart Richmond has been awarded a research prize by the Ministry of Health NCCRCD (UK). In his article [33], the English scholar commented on Segal's study: "The results presented by Segal and his colleagues can be challenged on the basis of poorly planned research and lack of statistical criteria. Their research shows a number of other methodological weaknesses that characterize other studies of magnetic therapy. For example, a significant methodological drawback is that no consideration is given to the possible reduction in patient-administered analgesics, which may compromise the true benefit of magnetic therapy." In his detailed study, Dr. Richmond reported an improvement in pain in patients with rheumatoid arthritis $p=0.2$ ) after a static magnetic field effect, he considers this result as clinically relevant as quoted monograph data [34] that if the cost of prescription drugs for arthritis and disease-related complications can so can only be reduced by $1 \%$, this would result in annual savings for England approximately is $£ 3.4$ million.

Nathan, Kuipers, and others [35] make a study of arterial pressure, heart rhythm and pain sensation in patients aged 24-26 years. Eight men and 7 women are exposed to a magnetic field emanating from 95 magnet magnets with a $600 \mathrm{G}$ intensity located on a mattress. The effect of the magnetic field is 1 hour. The patients studied had a mean diastolic pressure of 91-93 $\mathrm{mmHg}$ and a heart rate of 62-63 beats per minute. The measured results after 1 hour on the magnetic mattress are $91 \pm 3,93 \pm 3$ $\mathrm{mmHg}$ and $63 \pm 2,62 \pm 2$ beats per minute respectively. The authors did not record significant changes in subjective symptoms when exposed to a permanent magnetic field of $600 \mathrm{G}$ force.

We will be able to analyze what Nathan et al. test because the results are relevant to our research.

Concerning the impact of the magnetic field on blood pressure and heart rhythm:

The magnetic field does not reduce arterial pressure and heart rhythm, it regulates them. This means that if their values are normal (without medication), no changes will be recorded in the study. If patients have indicators close to normal (no medication), then their changes will be minimal, i.e. statistically insignificant.

Those surveyed by Nathan, Quippers and others patients have normal heart rhythm and diastolic blood pressure values close to normal. Therefore, the registered minimum deviations are perfectly logical. In order to prove the influence of a magnetic field with larger changes in the values of the parameters studied, it is necessary for the volunteers to have greater deviations from the normal values.

There is another aspect of this study, which explains the lack of clinically meaningful results. For the magnetic field to be effective, it should be applied appropriately to the body, as Dr. Kiocchi Nakagawa points out [18]. Below we will analyze the appropriate place for attaching magnet to analgesia.

For effective effects on arterial pressure and heart rhythm, the magnetic field must affect blood circulation or combined on the bloodstream and the cranial sympathetic ganglia. For this purpose, it is best for the field emitted by the magnetic device to be continuous (rather than point), to operate in a closed loop, the device to be firmly attached to the body for maximum penetration of the field and to be applied in the correct place. To regulate blood pressure and heart rhythm, appropriate parts of the human body are neck and wrist. Permanent magnets placed on a mattress can compensate for accumulated magnetic deficits but are not a suitable therapy for the observed subjective symptoms.

\section{Concerning the pain-relieving effect of the magnetic field:}

We have already mentioned that the place where the magnetic device attaches is of paramount importance for the effectiveness of therapy [18]. With analgesia, the right place is close to the pain. The magnetic device must be placed between the 
cerebrum and the applied pain point, the path of the nerve impulses transmitting information from the peripheral nervous system to the brain. If these rules are not met, an analgesic effect is unlikely to occur within 1 hour. The scientific approach requires proper planning of the study, as well as a precise definition of the conclusions.

Casio Shimodira [36] examined 431 volunteers using mattresses with 126 permanent magnets with an intensity of 750 to $900 \mathrm{G}$. The volunteers were 216 men and 215 women divided into a core group of 375 and a control group of 56 volunteers. The control group uses mattresses with placebo magnets (0G) and the main one is divided into 6 parts according to the subjective symptoms:

1. neck and shoulder pain;

2. Lower back pain;

3. No localized back pain (pain across the back);

4. Lower leg pain;
5. Insomnia;

6. Fatigue and fatigue.

The test was conducted for a period of 12 months, when all groups are additionally observed the following parameters: hemoglobin, erythrocyte count, leukocyte count, content in the blood of: TR, COL, ALP, GOT, GPT, Na and K, blood pressure . The condition of kidney, liver, pancreas and blood system is controlled. The studied parameters and the state of the observed organs and systems were studied before the impact with a static magnetic field and at the end of the impact period (at the end of the 12th month). The subjective symptoms were reported at the end of the $3 \mathrm{rd}$, the 5 th month and the end of the period. During the first 3 months the magnetic field affected 200 volunteers. The average efficiency of all groups is $53.3 \%$. The data is shown in Table. 1.

Table 1

\begin{tabular}{|l|c|}
\hline \multicolumn{1}{|c|}{ Groups of symptoms } & Influenced volunteers, $\%$ \\
\hline 1. Neck and shoulder pain & 46.9 \\
\hline 2.Lower back pain & 50.0 \\
\hline 3. All-back pain & 38.7 \\
\hline 4. Lower leg pain & 54.4 \\
\hline 5. Insomnia & 64.3 \\
\hline 6. Fatigue and weakness & 57.6 \\
\hline
\end{tabular}

At the end of the 5th month, an average efficiency gain of $70 \%$ was reported. At the end of the 12-month study period, the total influenced volunteers of all groups were 301 people, not the

affected 74 people. The average efficiency is $80.27 \%$ and the proportion of non-affected volunteers is $19.73 \%$. Specific data by groups of symptoms are shown in Table 2.

Table 2

\begin{tabular}{|l|c|c|c|c|c|}
\hline \multicolumn{1}{|c|}{ Groups of symptoms } & $\begin{array}{c}\text { General } \\
\text { cases }\end{array}$ & $\begin{array}{c}\text { Influenced } \\
\text { volunteers }\end{array}$ & $\begin{array}{c}\% \text { Uninvolved } \\
\text { volunteers }\end{array}$ & $\begin{array}{c}\text { number of } \\
\text { people not } \\
\text { affected }\end{array}$ & $\begin{array}{c}\% \text { number of } \\
\text { people not } \\
\text { affected by all }\end{array}$ \\
\hline 1. Pain in the neck & 66 & 47 & 71.2 & 19 & 28.8 \\
\hline 2. Lower back pain & 76 & 61 & 80.3 & 15 & 19.7 \\
\hline 3. Pain on all back & 31 & 25 & 80.7 & 6 & 19.3 \\
\hline 4. Pain in the lower & 68 & 54 & 79.4 & 14 & 20.6 \\
\hline 5. Insomnia & 70 & 61 & 87.1 & 9 & 12.9 \\
\hline 6. Fatigue and weakness & 64 & 53 & 82.8 & 11 & 17.2 \\
\hline
\end{tabular}


There were no clinically significant changes in the additional observed signs, as well as changes in kidney, pancreas and liver function. Volunteers have reported improvement in the following subjective symptoms: tinnitus; headache; hearing problems; visual problems, vertigo; palpitations; problems with perceptions and digestive disorders.

The results obtained by Dr. Casio Shimodira [36] refute the conclusions of Nathan, Quipers, L. Chariti, L. Sauder and A. Chester [35]. One of the significant differences in the two studies is the influence time of the research factor. One hour to affect a permanent magnetic field with a force of less than $1000 \mathrm{G}$ is too small to record a result, especially if the rules for placing the magnetic device in the correct place depending on the controlled subjective symptom are not met.

Hinman, Ford (Ford) and others [37] organized a controlled clinical trial of 43 volunteers with randomized knee pain. Patients were divided into a primary and control placebo group and tested for two weeks. The conclusion is that "the application of static magnets to treat knee pain reduces pain and improves the duration and speed of movement (walks) of volunteers. However, a further study is needed to determine the physiological mechanisms leading to this analgesic effect."

Between December 2001 and December 2003, Harlow, Greaves, and others [38] recruit 194 participants aged 45-80 years with osteoarthritis of the thigh or knee. Volunteers are divided into 3 groups according to the source and impact strength:

Group A - neodymium magnets with a force of 170-200 mT (1700-2000 G)

Group B - weak magnets with a force of 21$23 \mathrm{mT}(210-230 \mathrm{G})$

Group C - Non-Magnetic Steel Washers.

Man D (Man D) and others [40], present their experience with the curative influence of northern magnetic posture on post operative wounds. Twenty patients after vaccinated lutectomy were examined after a randomized two-group primary and control placebo group. The patients are of both sexes aged between 18 and 75 years. A negative magnetic field (North Pole Field) with an intensity of 150 to $400 \mathrm{G}$ is used. Pattern magnets are placed on the base group (10 patients) on the operative zone. Placebo magnetic patches are used for the control group (10 people) in the same area. Pain, swelling and change in the color of the surgical wound are assessed at 1 , 2, 3, 4, 7 and 14 days after surgery. The results showed that the basal group had a significant reduction in pain in the postoperative period of 1 to
7 days, a 1 to 4 day swelling reduction and wound discoloration from 1 to 3 days compared to the control group.

The study demonstrates that the static field of the North magnetic pole has a positive effect on patients with vacuum wound lysectomy in the healing post-operative process.

Hinman [41] is conducting a study of 75 healthy volunteers - 52 women and 23 men aged 21-57, to determine how it affects the unipolar magnetic field on the healthy human body. Volunteers are exposed to magnets with a measured intensity of $500 \mathrm{G}$. Magnets are arranged with only one pole on the usable side of the mattress so as to provide a unipolar magnetic field in the contact area. The heart rhythm and blood pressure of the volunteers are studied. Their values are: heart rhythm between 64 and 71 beats per minute, diastolic blood pressure 71$75 \mathrm{mmHg}$ and systolic pressure 117-120 $\mathrm{mmHg}$. They are divided into three groups - exposed to the North magnetic pole, the Southern magnetic pole and the placebo group. Measurements of observed parameters were made before exposure to magnetic field after magnetic field impact during 1st, 5th, 10th and 15th minutes. The last measurement of the surveyed indicators was made 5 minutes after the cessation of the impact. The conclusion of the study is that "short-term exposure to a static magnetic field of positive or negative polarity does not cause clinically significant changes in heart rhythm and arterial pressure among asymptomatic individuals. This discovery supports the safe use of unipolar magnetic fields with a surface force of less than $1000 \mathrm{G}$ with respect to the cardiovascular system. "

The Hinman test is a classic example of an incorrectly planned test and we do not think the results have a scientifically relevant meaning.

1. Healthy volunteers are selected. As already commented, the magnetic field regulates heart rate and blood pressure values, rather than changing them arbitrarily. Proof of this is the study of Yuri Dmitrov [42, 43]. After selecting volunteers with almost normal indicators, there is no way to obtain statistically significant deviations of the parameters tested.

2. Magnets with a measured intensity of about $500 \mathrm{~g}$ are used. These intensity values are not sufficient to show a response within 5-15 minutes. The body response for such a short period can be recorded at mega fields around $2 \mathrm{~T}(20,000 \mathrm{G})$

3. Apart from the fact that the intensity of the magnets and the impact time are selected incorrectly, there is another major problem. The two 
poles of the magnets point to the two opposite sides of the mattress. This means that the magnetic field, closing between the two poles, has an insignificant scattering gradient to the usable side on which it lies and therefore penetrates insignificantly in the body.

We have drawn attention to the problems in the planning of the study, because much of the research on the influence of the magnetic field on living organisms and humans is of a similar quality, which casts doubt on their results and more precisely on the correctness of the conclusions.

Yuri Dmitrov [42] studies the effect of a static magnetic field on arterial pressure. He studied 16 rabbits with pentobarbital. At the neck, a magnetic device with a force of $2000 \mathrm{G}$ is provided on the artery to stimulate the baroreceptors of the carotid artery. The state of hypertension is maintained by intravenous infusion of noradrenaline. Noradrenaline elevates blood pressure, then activates the magnetic field, which acts for 35 minutes. The mean femoral pressure drops by $10 \%$. The constant magnetic field influences the arterial pressure in the direction of normalization of its values.

Another study was conducted by Yuri Dmitrov [43] of 15 rabbits again placed under pentobarbital anesthesia. The reflex center of the aorta nerve on the right ear of the rabbits is stimulated by a nozzle providing pressure (acupressure) and emitting electrical impulses. The aim is to stimulate blood pressure reduction by baroreceptor regulation. After the drop in blood pressure values, the magnet on the carotid artery with a force of $2000 \mathrm{G}$ is activated for 40 minutes. The magnetic field increases the blood pressure by $14.1 \%$, approaching the normal limit.

In this test, the permanent magnetic field again affects the normalization of blood pressure, which proves its therapeutic potential.

Hypertension, including its mild form (160/100 $\mathrm{mmHg}$ ), is a disease causing serious complications. Patients with mild hypertension are $70 \%$ of all those suffering from high blood pressure [44]. The disease regresses in the most severe cardiovascular complications (heart attack and stroke) as well as functional disorders of the heart, kidneys, and atherosclerotic lesions of the peripheral vessels. Brain vascular diseases are diagnosed in $20 \%$ of working-age people, of whom $65 \%$ suffer from arterial hypertension and $60 \%$ of patients with impaired cerebral circulation have a mild form of hypertension [45].

$\mathrm{Yu}$. Mikhailovich and others [46] investigate the effectiveness of a "running" magnetic field for the control of light hypertension $(160 / 100 \mathrm{mmHg})$ as it acts on cervical sympathetic ganglia using a $50 \mathrm{~Hz}$ magnetic field emitter bandwidth to provide magnetic force a range of 150 to $600 \mathrm{G}$ (15 to 60 $\mathrm{mT})$. Seventy five patients with mild hypertension 28 males and 47 women with mean age $51 \pm 5.2$ years with a disease duration of 3 to 18 years are divided into three groups:

I. group of 29 people with a banded electromagnetic emitter placed over the cranial ganglia of the sympathetic system;

II. group of 28 people with attached electromagnetic shoulder radiator;

III. placebo group of 18 volunteers with a dummy device attached to the sympathetic cervix ganglia.

A hypotensive effect on the blood pressure of Group I patients was found in 23 subjects $(79.3 \%)$, systolic pressure dropping from $155 \pm 6.2 \mathrm{mmHg}$ to $129 \pm 2.4 \mathrm{mmHg}(\mathrm{p}<0.01)$, diastolic pressure changed from $98.4 \pm 3.7 \mathrm{mmHg}$ to $82.6 \pm 2.9 \mathrm{mmHg}$ (p \& 1t; 0.01).

In group II improvement in 19 patients $(67.8 \%)$ with a systolic pressure decrease from $157.2 \pm 6.2$ to $143.1 \pm 2.4 \mathrm{mmHg}(\mathrm{p}<0.01)$ and diastolic from 97.2 \pm 4.3 to $87.6 \pm 1.6 \mathrm{mmHg}(\mathrm{p}<0.05)$.

In the III placebo group, a reduction in systolic blood pressure of $155.2 \pm 6.2$ to $149.0 \pm 2.3 \mathrm{mmHg}$ and diastolic from $96.2 \pm 2.4$ to $92.1 \pm 1.6 \mathrm{mmHg}$ (p $<0.05$ ).

Normal blood pressure values (lower than $130 / 85 \mathrm{mmHg}$ ) were achieved only in patients of the 1st group. For one month, the volunteers from this group reached up to 25 people $(86.2 \%)$.

The results of the study give grounds for $\mathrm{Yu}$. Mikhailovich and others. recommend the method of magnetic correction of sympathetic ganglia to treat mild hypertension and prevent the risk of developing severe cardiovascular disease.

From the brief review we can draw the following categorical conclusions:

1. A permanent magnetic field with a force below $3000 \mathrm{G}$ is not harmful to the body. There is no research and literary source to question this fact.

2. A permanent magnetic field with a force between 10 and $3000 \mathrm{G}$ affects living organisms and humans $[1,5,6,7,15,18-31,33,36,38,39,40$, $42,43,46]$.

3. The magnetic field has a therapeutic effect [5, $6,7,18-31,33,36,38,40,42,43,46]$.

4. The magnetic field affects the circulatory and cardiovascular system $[10,11,12,42,43,46]$.

These conclusions are sufficient grounds to declare a destructive argument about the usefulness 
of the permanent magnetic field. We think it is wise to replace this insubstantial discussion with a debate on the possibilities of using the influence of the magnetic field for the benefit of human health, such as possible prophylaxis and concomitant therapy. Of course, a matter of scientific research is to specify the optimal parameters for impact on each person and a specific subjective symptom.

\section{REFERENCES}

1. The World Health Organization - Geneva, 1987. http://www.inchem.Org/documents/ehc/ehc/ehc69.ht m\#SubSectionNumber:4.1.2

2. Trong-Kha Truong, Bradley D. Clymer, Donald W. Chakeres, Petra Schmalbrock. ThreeDimensional Numerical Simulations of Susceptibility-Induced Magnetic Field Inhomogeneities in the Human Head at 8 Tesla/Departments of Radiology and Electrical Engineering. The Ohio State University, Columbus, OH, USA.

3 Brittenham G.M, Farrell D.E., Harris J.W., Feldman E. S., Danish E.H., Muir W.A., Tripp J. H., Bellon E. M., "Magnetic-Susceptibility Measurement of Human Iron Stores" N Engl J Med, 1982; 307:1671-1675December 30, 1982, DOI: 1056/ NEJM198212303072703

4. Holodov Yu. A, N.N. Lebedeva, Reactions nervous system man on electromagnetic field. Moscow, Science, 1992.

5. Saunders Richard, Static magnetic fields: animals studies. Prog. Biophys. Mol. Biol.q 2005 Feb-Aprq 87 (2-3), 225-39.

6. Davis, Albert Roy, Rowles, W., Magnetism and Its Impact on Living Organisms, Hicksville, Exposition Press, 1974, 29 p.

7. Ganshiam Sing Birla, Colelet Hamlin. Magnetotherapy, Medicine and Physical Education, 2004, $44 \mathrm{pp}$.

8. Piruzhan L.A., Kuznetsov A.H., Announcement AN USSR, Biological Series, (6) 805, 1983.

9. Jehenson, P., Duboc D., Lavergne T., Guize L., Guerin, F., Change in human cardiac rhythm induced by a 2-T static magnetic field. Radiology, 1988 - pubs.rsna.org

10. Yousef Haik, Vinay Pai и Ching-Jen Chen. Apparent viscosity of human blood in a high static magnetic field/Journal of Magnetism and Magnetic Materials, Vol. 225, Issues 1-2, 2001, pp. 180-186.

11. Misra C., Sinha A, Shit G. C., Mathematical modeling of blood flow in a porous vessels having double stenoses in the presence of an external magnetic field/ Int. J. Biomath. 04, 207 (2011). DOI: 10.1142/S1793524511001428

12. Varshney G., Katiyar V., Kumar S., Effect of magnetic field on the blood flow in artery having multiple stenosis: a numerical study International Journal of Engineering, Science and Technology, vol. 2, No 2, 2010.

13. Grisset J.D. Biological effect of electric and magnetic fields associated with ELE communication system/Proc. JEEE - 1980, vol. 68, pp. 98-104.

14. Stratznigg A. Ergebnisse einer klinishen Studie uber Magnetfeldtherapie Erfahrungsheikunde/ Ludwig - Boltmann - Inst. f. Akupunktur, Wien - 1985 Bd. 134 - S. 673-677.

15. Binggi B.H., Savin A.V., "Physical Problem Actions Low Magnetic Field of Biological Systems / Success Physical Science, March 2003, Vol. 173, N 3.

16. Adair R.K. Phys. Rev. A43 1039 (1991)

17. Pickard W.F, Moros F.G. „Bioelectromagnetics" 2297/2001.

18. Nakagawa, K. Magnetic Field Deficiency Syndrome and Magnetic Treatment. Japan Medical Journal No. 2745, December 4th, 1976.

19. Nakagawa, K., et al. Japanese Journal of Internal Medicine, 47(1), 76 (abstract), 1958.

20. Nakagawa, K. Japan Medical Journal (Nippon Iji Shimpo), 1891, 116-117, 1960.

21. Nakagawa, K. Compilation of Questions and Answers/ II, 8, Orthopedics, (Nishi, S. supervision), 8-12, Chugai Medical Publication, 1962.

22. Nakagawa, K. Report on 2nd Congress on "Magnetism and Living Bodies", 1959.

23. Nakagawa, K. (Edited By): Symposium on "Magnetism and Living Bodies", Daily Industrial News Co. (Nikkan Koryo Shimbunsha), 1973.

24. Nakagawa, K. Journal of The Society of Non-Traditional Technology, 66, -17, 1974.

25. Nakagawa, K., et al. Report on 2nd Conference on "Magnetic Fields and Living Bodies", 27-32, 1975.

26. Horie, S. Report on 3rd Conference on "Magnetic Fields and Living Bodies", (3), 1976.

27. Shimohira, K, et al.: -do-, (4), 1976.

28. Takahashi, N.: -do-, (6), 1976.

29. Nakagawa, K. Report of Japan Science Promotional Committee, Applied Magnetism, 137 Committee, No. 34 Meeting, 1974, 29-39.

30. Ohta, H. Pharmacology and Treatment, 3(9), 1750-1752, 1975.

31. Baba, H.: Literature submitted to Ministry of Health and Welfare, Japanese government, 1975.

32. Segal N., Toda Y., Huston J., Saeki Y., Shimizu M., Fuchs H., Shimaoka Y., Holcomb R., McLean M.J. „Two configurations of static magnetic fields for treating rheumatoid arthritis of the knee: a double-blind clinical trial" / Arch Phys. Med. Rehab. 2001 ;82:1453- 60.

doi: 10.1053/apmr. 2001.24309. [PubMed] [Cross Ref] 
33. Stewart J Richmond. Magnet therapy for the relief of pain and inflammation in rheumatoid arthritis (CAMBRA): A randomized placebocontrolled crossover trial/Journal List Trials v. 9, 2008 PMC 2556642, published online 2008 Sept. 12. doi: 10.1186/1745-6215-9-53, http://www.ncbi.nlm.nih.gov/pmc/articles/PMC2556642/

34. Arthritis Research Campaign Arthritis: the big picture [monograph on the internet] Chesterfield: Arthritis Research Campaign. 2002. http://www.ipsos-mori.com/ assets/polls/2002/pdf/ arthritis.pdf [cited 08/01/05], [last accessed 08/06/08]

35. Nathan T. Kuipers, Charity L. Sauder, Chester A. Ray, Influence of static magnetic fields on pain perception and sympathetic nerve activity in humans, J. Appl. Physiol. 102: 1410-1415, 2007/First published December 28, 2006; doi:10.1152/japplphysiol.00734.2006.

36. Kazuo Shimodaira. Summary of a 12 month double blind clinical test of magnetic mattress pads, Токуо Communication Hospital, Obstetrics and Gynecology/Tokyo, Japan, 1990.37. Hinman MR, Ford J, Heyl H. „Effects of static magnets on chronic knee pain and physical function: a double-blind study/Alternat Ther Health Med. 2002; 8: 50-5.

38. Harlow T, Greaves C, White A, Brown L, Hart A, Errist E. Randomised controlled trial of magnetic bracelets for relieving pain in osteoarthritis of the hip and knee/Br. Med. J. 2004; 329:1450-4.
39. Wolsko P.M, Eisenberg D.M, Simon L.S, Davis R.B, Walleczek J, Mayo-Smith M. et al. Double-blind placebo-controlled trial of static magnets for the treatment of osteoarthritis of the knee/Altern Ther Health Med. 2004.

40. Man D, Man B, Plosker H, ,The influence of permanent magnetic field therapy on wound healing in suction lipectomy patients: a double-blind study, med. Appl" /Published in: Plast Reconstr Surg 1999; 104(7): 261-2266 (PubMed.Journal website).

41. Hinman M.R. Comparative effect of positive and negative static magnetic fields on heart rate and blood pressure in healthy/ Adults. Clin. Rehabil. 2002;16: 669-740.

42. Gmitrova A, Gmitrov J. Effect of a permanent magnetic field on blood pressure regulation. Bioelectricity. 1990, 9: 79-83.

43. Gmitrov J., Ivanco I., Gmitrova A. Magnetic field effect on blood pressure regulation/Physiol Bohemoslov. 1990; 39: 327-334.

44. Alexeyev A.A., Laryonova I.C., Dubiniina H.A. Systemic medicine (from whomever lost the humanity) / per. with English 3rd Ed. M., 2000.

45. Gogin E.E. Hypertonic disease. M., 2000. (In Russian)

46. Mikhailovich R.Yu., Bolotov N.V., Lukyyanov V.F., Kompaniets O. V., Magnitnaya simpatokorrektsiya at myagkoy arterialynoy gipertonii/physiotherapy, rehabilitation and balyneologiya, N 2/2014.

\title{
ВЛИЯНИЕ НА МАГНИТНОТО ПОЛЕ ВЪРХУ ЖИВИТЕ ОРГАНИЗМИ И ЧОВЕКА
}

\author{
Стефан Найденов, Соня Петкова, Петър Гецов, Гаро Мардиросян
}

\begin{abstract}
Резюме: Въпросът за влиянието на магнетизма върху биологични обекти от години е дебат с много противоречиви мнения. В статията се прави кратък обзор на публикации и различни, и противоречиви становища за влиянието на магнитното поле върху живите организми и човека. Търси се обяснение за изключващите се констатации направени в различни научни изследвания, както и отговор на въпроса: „Може ли постоянното магнитно поле да бъде полезно за нашето здраве и при какви условия?"
\end{abstract}

Ключови думи: магнитно поле, здраве, диагностика, физиотерапия, физиологична реакция

\section{Stefan Naydenov, Sonia Petkova \\ Phone: 359888160111 \\ E-mails: advert_reg@bemagnetic.eu}

\section{Petar Getsov, Garo Mardirossian}

Space Research and Technology Institute -

Bulgarian Academy of Sciences

Acad. G. Bonchev Str, bl. 1

Sofia 1113, Bulgaria

E-mails: getsovp@space.bas.bg, mardirossian@space.bas.bg

\section{Стефан Найденов, Соня Петкова \\ Phone: 359888160111 \\ E-mails: advert reg@bemagnetic.eu}

\section{Петър Гецов, Гаро Мардиросян}

Институт за космически изследвания и технологии, Българска академия на науките

ул. „Акад. Г. Бончев“, бл. 1

София 1113, България

E-mails: getsovp@space.bas.bg , mardirossian@space.bas.bg 